\title{
Improved delivery of the anticancer agent citral using BSA nanoparticles and polymeric wafers
}

This article was published in the following Dove Press journal: Nanotechnology, Science and Applications

\author{
Benjamin White \\ Anna Evison' \\ Eszter Dombi ${ }^{1}$ \\ Helen E Townley ${ }^{1,2}$ \\ 'Nuffield Department of Obstetrics \\ and Gynaecology, Women's Centre, \\ John Radcliffe Hospital, ${ }^{2}$ Department \\ of Engineering Science, Oxford \\ University, Oxford, UK
}

\begin{abstract}
Rhabdomyosarcoma (RMS) is the most common soft tissue sarcoma in children, with a 5-year survival rate of between 30 and $65 \%$. Standard treatment involves surgery, radiation treatment, and chemotherapy. However, there is a high recurrence rate, particularly from locoregional spread. We investigated the use of the natural compound citral (3,7-dimethyl2,6-octadienal), which can be found in a number of plants, but is particularly abundant in lemon grass (Cymbopogon citratus) oil, for activity against immortalized RMS cells. Significant cancer cell death was seen at concentrations above $150 \mu \mathrm{M}$ citral, and mitochondrial morphological changes were seen after incubation with $10 \mu \mathrm{M}$ citral. However, since citral is a highly volatile molecule, we prepared albumin particles by a desolvation method to encapsulate citral, as a means of stabilization. We then further incorporated the loaded nanoparticles into a biodegradable polyanhydride wafer to generate a slow release system. The wafers were shown to degrade by $50 \%$ over the course of 25 days and to release the active compound. We therefore propose the use of the citral-nanoparticle-polymer wafers for implantation into the tumor bed after surgical removal of a sarcoma as a means to control locoregional spread due to any remaining cancerous cells.
\end{abstract}

Keywords: citral, nanoparticle, wafer, biodegradable, mitochondria, toroidal, cancer, rhabdomyosarcoma, Cymbopogon citratus

\section{Introduction}

Citral occurs abundantly in the oil of lemon grass (Cymbopogon citratus; 75-85\%), and is also present to a limited extent in the oils of Verbena, lemon, lime, orange, and ginger root. ${ }^{1}$ In vitro studies have reported on the ability of citral to induce cell death in breast cancer and leukemia cells., ${ }^{2,3}$ A number of different cell lines have shown the IC50 of citral to be between 20 and $50 \mu \mathrm{M}$. This can be compared with a study showing the same cell lines to have an IC50 for cisplatin of between 5 and $15 \mu \mathrm{M} .{ }^{4}$

Notably, citral has also been reported to be less cytotoxic towards normal mammary epithelial cells (MCF10A) than breast cancer cell lines MCF7 and MDA-MB-231, suggesting a cancer-specific effect. ${ }^{5}$ The citral molecule is relatively small and hydrophobic and diffuses freely through the cell membranes. Citral is also a strong electrophile because of its $\alpha, \beta$-unsaturated carbonyl functionality, ${ }^{6}$ and can be readily metabolized by mammalian cells. ${ }^{7}$

Essential oil constituents, such as citral, are frequently degraded by oxidation, isomerization, cyclization, or dehydrogenation reactions, triggered either enzymatically or chemically. ${ }^{8}$ The nanoparticle encapsulation of such compounds can be a
Correspondence: Helen E Townley Nuffield Department of Obstetrics and Gynaecology, Level 3, Women's Centre, John Radcliffe Hospital, Oxford, OX3 9DU, UK

Tel +44 I865 283792

Fax +44 I865 769 ।4I

Email Helen.Townley@eng.ox.ac.uk 
way to improve the physical stability, protect them from interactions with the environment, and decrease volatility. ${ }^{9}$ In this study, we have chosen to investigate the encapsulation of citral in nanoparticles made from bovine serum albumin (BSA). BSA is a natural protein that is biocompatible, biodegradable, nontoxic, and non-immunogenic. ${ }^{10}$ Human serum albumin (HSA) shows approximately $75 \%$ homology with BSA, and the 3D structure is also believed to be similar to that of BSA. ${ }^{11}$ We therefore selected BSA due to its low cost, ready availability, and similarity to HSAs. As a further step, we incorporated the nanoparticles into polymeric wafers for localized chemotherapy to the bed of the tumor after surgical removal to destroy any remaining cancerous cells. There are a number of potential benefits to localized treatment such as the controlled and prolonged release of drug, direct delivery to the disease site, and diminished side effects due to the avoidance of systemic circulation of the chemotherapy agents. ${ }^{12}$ In addition, the prolonged exposure of cells to chemotherapy may be more cytotoxic than bolus delivery since only $10-15 \%$ of tumor cells are expected to be in the mitotic phase of cell division at any one time..$^{13,14}$ This is especially important since the primary cause of death for many patients with soft tissue sarcomas is locoregional recurrence following curative resection.

In this study, we have further investigated the anticancer potential of citral against rhabdomyosarcoma (RMS) cell lines, and incorporated the compound into both nanoparticles and polymer wafers for improved delivery.

\section{Materials and methods Materials}

Citral (3,7-dimethyl-2,6-octadienal), BSA, glutaraldehyde, Tween 20, and sebacic acid (SA) were purchased from Sigma (Poole, UK).

\section{Preparation of BSA nanoparticles by desolvation method}

BSA (400 mg) was dissolved in $\mathrm{ddH}_{2} \mathrm{O}$ to a final concentration of $50 \mathrm{mg} / \mathrm{ml}$. The $\mathrm{pH}$ was then adjusted to 8 using dilute $\mathrm{NaOH}$. Tween 20 was added to a final concentration of $1 \% \mathrm{v} / \mathrm{v}$ for steric stabilization. The solution was stirred at $500 \mathrm{rpm}$ for $30 \mathrm{~min}$ before adding ethanol dropwise until the solution became turbid (ideally $4: 1 \mathrm{v} / \mathrm{v}$ ). Glutaraldehyde was then added and the solution was stirred for further $24 \mathrm{~h}$ $(0.4 \% \mathrm{v} / \mathrm{v})$. Particles were then centrifuged, washed with phosphate-buffered saline (PBS), resuspended in water, and lyophilized.

\section{Methods}

\section{Citral loading of BSA nanoparticles}

Nanoparticles were prepared as in section "Preparation of BSA nanoparticles by desolvation method" above with the dropwise additions of pure $(5.8 \mathrm{M})$ citral while stirring at $500 \mathrm{rpm}$ for $30 \mathrm{~min}$ until total addition achieved a 100:1 citral:BSA molar ratio. The product was denoted as BSA@, citral.

\section{Determination of encapsulation efficiency and loading capacity}

To determine the maximum load of citral onto the BSA particles,25mg of BSA@citral nanoparticleswere incubated in $5 \mathrm{ml}$ trypsin for $24 \mathrm{~h}$ at $37^{\circ} \mathrm{C}$. This trypsin should completely dissolve the BSA and release the citral. After the incubation period, the suspension was centrifuged to ensure that any particulate matter was removed. Since the trypsin present would interfere with UV, a titration method was used to assess the amount of citral. The supernatant was then mixed with $20 \mathrm{ml}$ ethanol, $10 \mathrm{ml}$ hydroxylamine, and $0.4 \mathrm{ml}$ bromothymol solution; this yellow colored solution was then stirred for $15 \mathrm{~min}$ at $500 \mathrm{rpm}$. Subsequently the solution was titrated against $0.05 \mathrm{M}$ potassium hydroxide until the solution turned turquoise in color. The titration was repeated 3 times and the results were compared to a calibration curve.

In order to determine the release of citral from the particles into an aqueous solution over time, $25 \mathrm{mg}$ of particles were suspended in $5 \mathrm{ml}$ PBS and stored in dialysis tubing; the tubing was left in $40 \mathrm{ml}$ PBS and constantly stirred. The amount of citral that was released into the PBS was measured by UV absorption at $230 \mathrm{~nm}$ (Cary 2000 UV-VIS spectrometer).

To determine the encapsulation efficiency, the following equation was used:

$$
\mathrm{EE}=\frac{\text { Moles taken up by } 400 \mathrm{mg}}{\text { Total moles added in synthesis }} \times 100
$$

Encapsulation efficiency was determined in the standard synthesis where $400 \mathrm{mg}$ of nanoparticles were synthesized and $680 \mu \mathrm{M}$ of citral was added.

\section{Determination of the volatility of citral}

The volatility of the citral was determined using the equation $K_{H}^{p c}=p / \mathrm{c}_{\mathrm{a}}$ for Henry's law volatility constant, where $p$ is the partial pressure of citral and $c_{a}$ is the aqueous concentration. The partial pressure of citral was determined by measuring the decay in weight of citral in aqueous solution as outlined 
by the equation $\mathrm{E}=-\frac{\mathrm{dm}}{\mathrm{dt}}=p\left(\frac{\mathrm{M}}{2 \pi \mathrm{RT}}\right)^{0.5},{ }^{21}$ where $\mathrm{E}$ is the decay of weight of citral in aqueous solution in $\mathrm{g} \mathrm{s}^{-1} \mathrm{~m}^{-2}, \mathrm{~T}$ is the absolute temperature in Kelvin, and $\mathrm{M}$ is the molarity in $\mathrm{mol} \mathrm{dm}^{-3}$.

\section{Cell culture}

The biological effect of citral was tested in vitro on RMS immortalized cancer cell lines obtained from the American Type Culture Collection (ATCC; Manassas, VA, USA). The two cell lines tested were RD (ATCC code CCL-136) and RH30 (ATCC code CRL-7763). Cells were grown in growth medium (Dulbecco's modified Eagle's medium [Sigma-Aldrich]) supplemented with 10\% fetal calf serum (Sigma-Aldrich), 2 mM L-glutamine (Sigma-Aldrich), 100 $\mathrm{U} / \mathrm{ml}$ penicillin (Sigma-Aldrich), and $0.1 \mathrm{mg} / \mathrm{ml}$ streptomycin (Sigma-Aldrich) and then incubated at $37^{\circ} \mathrm{C}$ in a $5 \% \mathrm{CO}_{2}$ atmosphere. Cells were passaged every 3-4 days.

\section{Crystal violet assay}

Cells were seeded in 96-well plates at $1 \times 10^{4}$ cells/well in growth media and left overnight in the incubator for the cells to adhere. The following day cells were treated for 24 $\mathrm{h}$ with concentrations between 1 and $1000 \mu \mathrm{M}$ citral. After treatment, the media on the cells was removed and the cells were washed in PBS twice. Cells were fixed in $100 \mu \mathrm{l}$ of $1 \%$ (v/v) glutaraldehyde (aq; Sigma-Aldrich) for $30 \mathrm{~min}$ and stained with $100 \mu \mathrm{l}$ of $0.5 \%(\mathrm{w} / \mathrm{v})$ crystal violet solution (aq; Sigma-Aldrich) for at least $1 \mathrm{~h}$. The plate was washed with water and dried overnight and cells were solubilized using $150 \mu \mathrm{l}$ of solubilizing solution $(1 \%[\mathrm{w} / \mathrm{v}]$ sodium dodecyl sulfate [Fisher Scientific]) and 10\% (v/v) acetic acid (Sigma-Aldrich)]. The absorbance of the solution was measured at $590 \mathrm{~nm}$ using a Tecan Infinite 200 microplate reader. Samples were blank corrected and expressed as a percentage of the control cell viability. Experiments were performed in triplicates and repeated on three separate occasions.

\section{Automated high throughput image acquisition and analysis}

Cells were seeded in 96-well plates at $7.5 \times 10^{3}$ cells/well in growth media and left overnight in the incubator for the cells to adhere. The following day cells were treated for $24 \mathrm{~h}$ with either PBS or $0.1-100 \mu \mathrm{M}$ citral, in triplicates. Cells were then washed in PBS, fixed in 4\% paraformaldehyde for $15 \mathrm{~min}$, washed again in PBS, and left in PBS until staining. The mitochondria were stained with TOM20 (Santa Cruz Biotechnology) and the nucleus with DAPI. Alexa Fluor secondary antibodies were used to stain the mitochondria red (Alexa Fluor 488; Life Technologies). Staining was performed within 7 days of fixing. Image acquisition was performed using an automated imaging platform IN Cell Analyzer 1000 (GE Healthcare Life Sciences) equipped with a Nikon Fluor ELWD $40 \times 0.6$ objective. Six fields of view were taken from each well in two fluorescence modes (TRITC and DAPI). Raw images were processed and parameters obtained using a customized protocol in the IN Cell Developer toolbox software (GE Healthcare Life Sciences). Cells were segmented using DAPI (cell nuclei) and properties of the mitochondria were obtained. The total area of the mitochondria and the nuclei was assessed. Experiments were performed in triplicates and repeated on at least two separate occasions.

\section{Polymer synthesis and degradability Synthesis of polyanhydride}

SA granules $(0.1 \mathrm{~g})$ and acetic anhydride $(0.3 \mathrm{~g})$ were mixed in a microwaveable vial. The mixture was then microwaved at medium intensity for $2 \mathrm{~min}(1100 \mathrm{~W})$ while sealed. After cooling, excess acetic anhydride was removed via vacuum desiccation. The remaining mixture was microwaved for further $5 \mathrm{~min}$ with no cap on the vial to allow any anhydride to escape and ensure full polymerization. The polymer was then allowed to cool and set into a white solid.

\section{Nanoparticle loading into wafer}

The synthesized polyanhydride $(0.3 \mathrm{~g})$ described in section "Synthesis of polyanhydride" above was dissolved in $5 \mathrm{ml}$ of acetone. Either BSA or BSA@citral nanoparticles (25 mg) were resuspended in $5 \mathrm{ml}$ acetone and agitated on a rocking table at $100 \mathrm{rpm}$ while the solvent evaporated. The resulting powder was compressed at 5 tons pressure in a worktop hydraulic press into a $1 \mathrm{~mm}$ thick and $14 \mathrm{~mm}$ diameter disc.

\section{Degradability of wafer}

BSA@citral-loaded nanoparticle polymer wafer and control unloaded polymer wafer were each placed in $40 \mathrm{ml}$ PBS and incubated in a shaking incubator at $37.5^{\circ} \mathrm{C}$. At defined time intervals, the supernatant was removed and the polymer carefully dried and weighed, after which the polymer wafers were re-submerged in $40 \mathrm{ml}$ of fresh PBS. This was done in order to mimic the movement of fluid in the body. The supernatant components were separated via dialysis for $48 \mathrm{~h}$ and the citral content determined by UV spectrometry. 


\section{Gas chromatography}

Detection of citral by gas chromatography was performed using a Shimadzu GC 2010. The samples were separated with a ZB-FFAP column (Zebron, Phenomenex) and coupled to an FID detector. An optimized protocol to give a clear unmasked signal for both citral isomers (geranial and neral) was as follows; temperature maintained at $50^{\circ} \mathrm{C}$ for $2 \mathrm{~min}$, followed by ramping to $250^{\circ} \mathrm{C}$ at a rate of $50^{\circ} \mathrm{C}$ per minute. This temperature was then maintained for $4 \mathrm{~min}$ to ensure complete flushing of the column. The peaks representing geranial and neral were seen at 6.02 and $6.19 \mathrm{~min}$, respectively. Integration of the area under the peaks was used to determine concentration of each isomer present.

\section{Physical characterization}

Scanning electron microscopy (SEM) was used to characterize the wafers using a Carl Zeiss LS15 VP machine at 15 $\mathrm{kV}$. SEM specimens were sputter coated with a $5 \mathrm{~nm}$ layer of Au-Pd.

The hydrodynamic diameter of the nanoparticles was measured using a CPS disc centrifuge (DC 18000; CPS Instruments Europe, Oosterhout, the Netherlands). The machine was operated at $24,000 \mathrm{rpm}$, and sucrose density gradient ranging from $8 \%$ to $24 \%(\mathrm{w} / \mathrm{v})$ was built up by injecting decreasing concentrations of sucrose into the centrifuge. The highest density layer must be of lower magnitude than the density of the particles in the sample or the particles will not arrive at the detector. Samples $(100 \mu l)$ was inserted into the center of the discs and the time taken to reach the outside of the disc measured. The size distribution can then be calculated based on the density of the particles (assumed to be the bulk tabulated density) and the rotation speed. Samples were prepared by resuspending the nanoparticles in double distilled water, sonicating with an ultrasonic probe (sonic Vibra-Cell) for 5 $\min (104 \mathrm{~W}[80 \%] 5 \mathrm{sec}$ on/5 sec off) and filtering with a 0.2 $\mu \mathrm{m}$ filter ( $33 \mathrm{~mm}$ cellulose acetate syringe filter, Anachem). Samples were calibrated against particles of a known diameter (polyvinyl chloride, $0.377 \mu \mathrm{m}$, CPS Instruments Europe).

The zeta potential of the nanoparticles was measured using a Malvern Zetasizer Nano. Samples were prepared at a concentration of $0.2-0.3 \mathrm{mg} \mathrm{ml}^{-1}$ in PBS.

\section{Statistical analysis}

Significance was tested using a two-tailed $t$-test comparing treated and untreated cells (not significant $p \geq 0.05,{ }^{*} p \leq 0.05$, $\left.{ }^{* *} p \leq 0.01,{ }^{* * *} p \leq 0.005\right)$.

\section{Results and discussion}

\section{Citral induces cell death in RMS cell lines}

The activity of citral was tested against two different RMS cell lines, RD and RH30. RH30 (ATCC no. CRL-2061) is an alveolar RMS and RD (ATCC no. CRL-7763) is an embryonal RMS. Citral was tested over a range of concentrations, and was shown to induce significant amounts of cell death at concentrations above $200 \mu \mathrm{M}$ in RH30 cells (Figure 1A), and $150 \mu \mathrm{M}$ in RD cells (Figure 1B).

\section{Citral causes changes in the mitochondria and nuclei of RMS cells}

Mitochondrial morphology

Since mitochondria are often essential for initiating apoptotic cell death, we studied the effect of citral on both mitochondrial morphology and the total area covered within the cell.

It has previously been demonstrated that citral shows antifungal activity against Penicillium digitatum and that the mitochondria from the fungi show a sunken surface and malformation when treated at the minimum inhibitory concentration. At the minimum fungicidal concentration, the citral-treated mitochondria collapsed severely, resulting in a lack of matrix, anomalous shape, disordered structure, and rough surface. ${ }^{15}$

In our study, the mitochondrial membrane was stained with TOM20 and images collected for analysis. Microscopic examination of the mitochondria in RMS cells after incubation with fairly low concentrations of citral $(10 \mu \mathrm{M})$ showed toroidal structures (Figure 2B). Toroidal mitochondrial have been observed in a number of other studies and the response was determined to be independent of cell type, and could occur in both primary and immortalized cell lines. Under hypoxic conditions, the process was shown to begin with the opening of the permeability transition pore (or $\mathrm{K}^{+}$channels), which caused mitochondrial swelling, and partial detachment from the cytoskeleton. ${ }^{16}$ This results in anomalous fusion events such as autofusion and fusion at several sites among 2-3 mitochondria. The partial detachment of the mitochondria from the microtubule tracks will also affect the movement of the mitochondria and may contribute to the retention of the organelles in the perinuclear region (also seen in our study; Figure 2A and B). It is thought that the toroidal structure is a protective mechanism that enables the mitochondria to tolerate matrix volume increases and can give rise to offspring that can regain the membrane potential.

However, at higher concentrations of citral, there is mitochondrial swelling up to $100 \mu \mathrm{M}$. It is probable that citral begins to release from calcium from stores such as the 
A

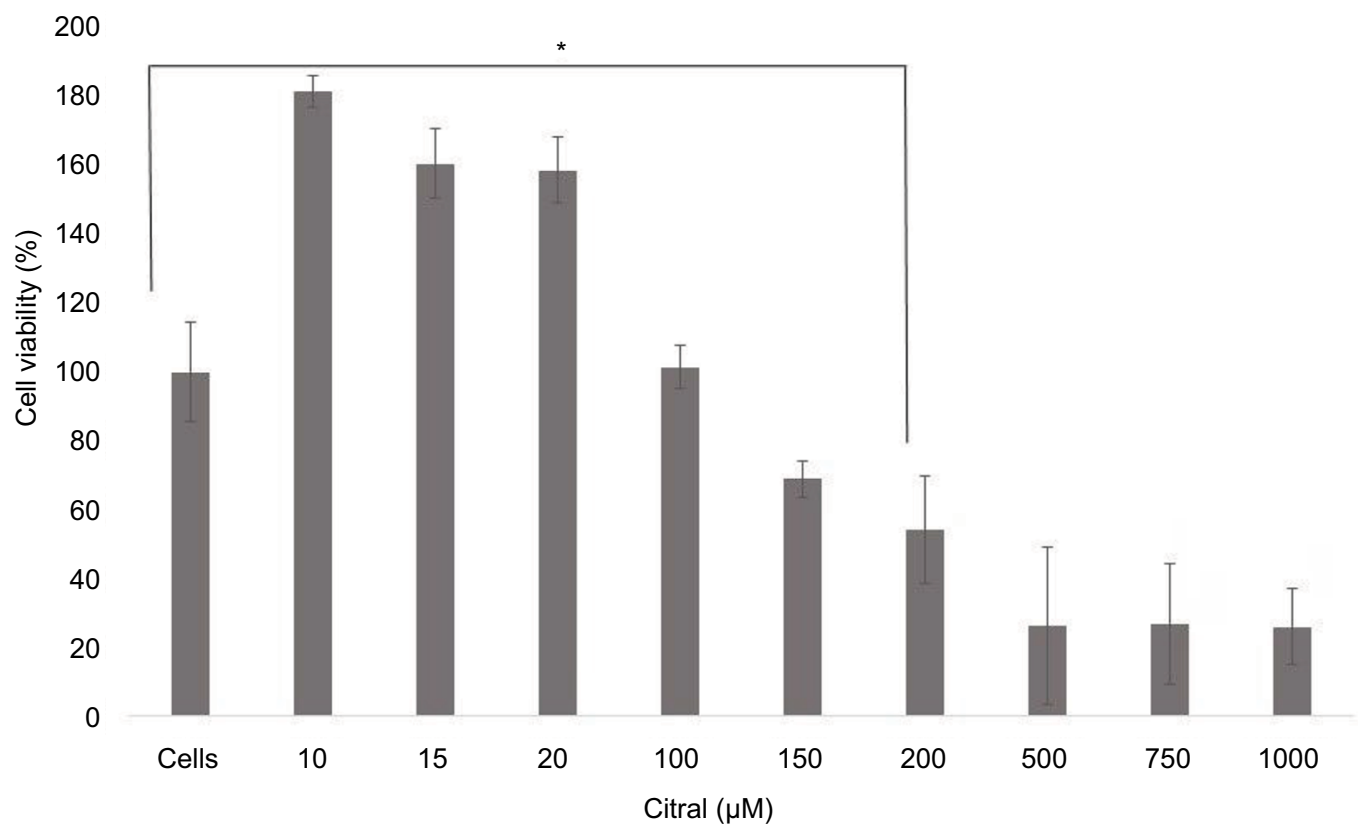

B

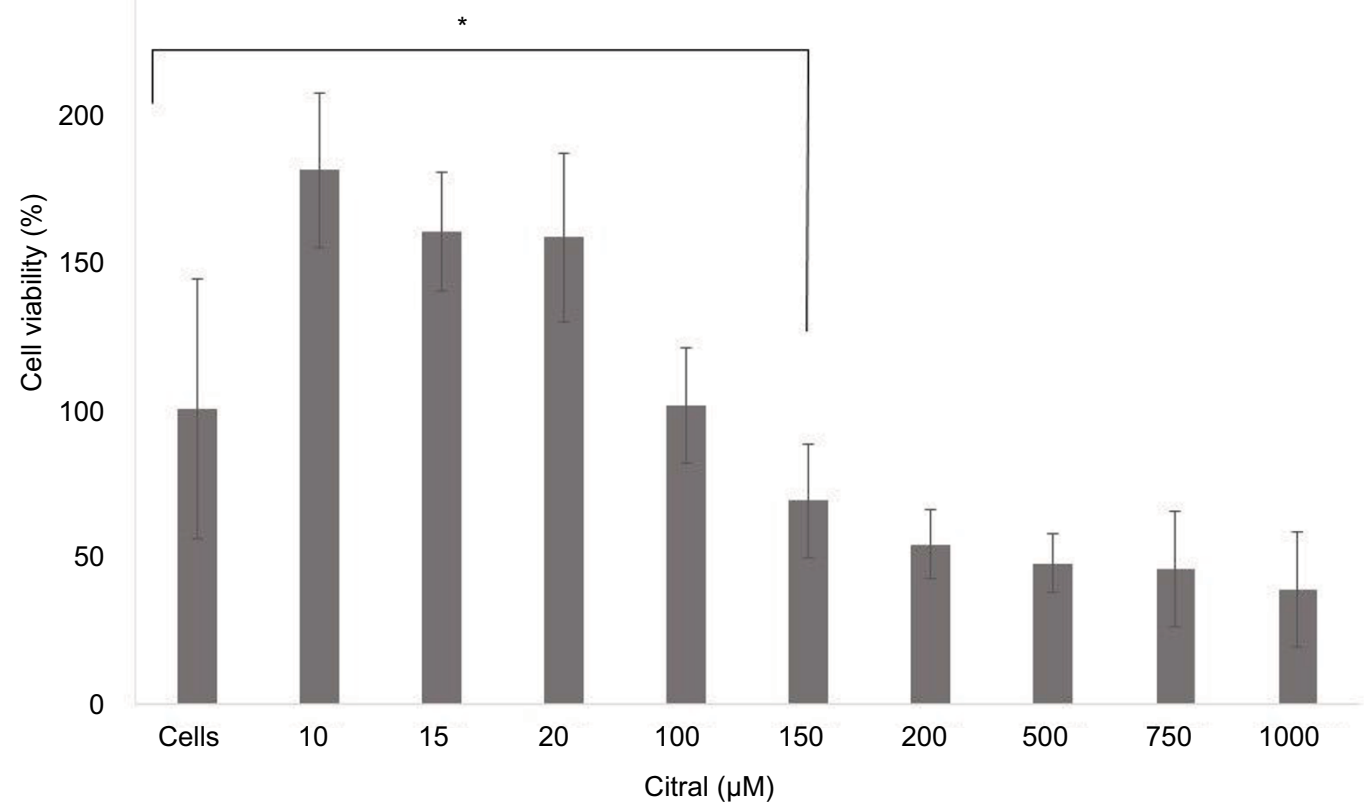

Figure I Cell viability was assessed in rhabdomyosarcoma cells in increasing concentrations of citral. (A) RH30 cells and (B) RD cells. The bar-labeled "cells" refer to the cell only control, and is set to $100 \%$. All data were scaled relative to the cell only control. Significance was tested using a two-tailed $t$-test compared to the untreated cells for each cell line $(* p \leq 0.05)$.

endoplasmic reticulum, which induces mitochondrial pore transition (MPT) opening, depolarization, and then uncouples oxidative phosphorylation and causes mitochondrial swelling. At higher concentrations, a threshold is reached and MPTinduced swelling of the matrix progressively engorges the compartment. This results in the inner mitochondrial membrane (IMM) which forms the cristae being stretched out flat. The outer mitochondrial membrane having a smaller surface area than the IMM ruptures when its distension limit is reached. ${ }^{17}$

\section{Mitochondrial and nuclear quantification}

Multiple images were analyzed using the IN Cell Analyzer Workstation software and data collected to show both the 

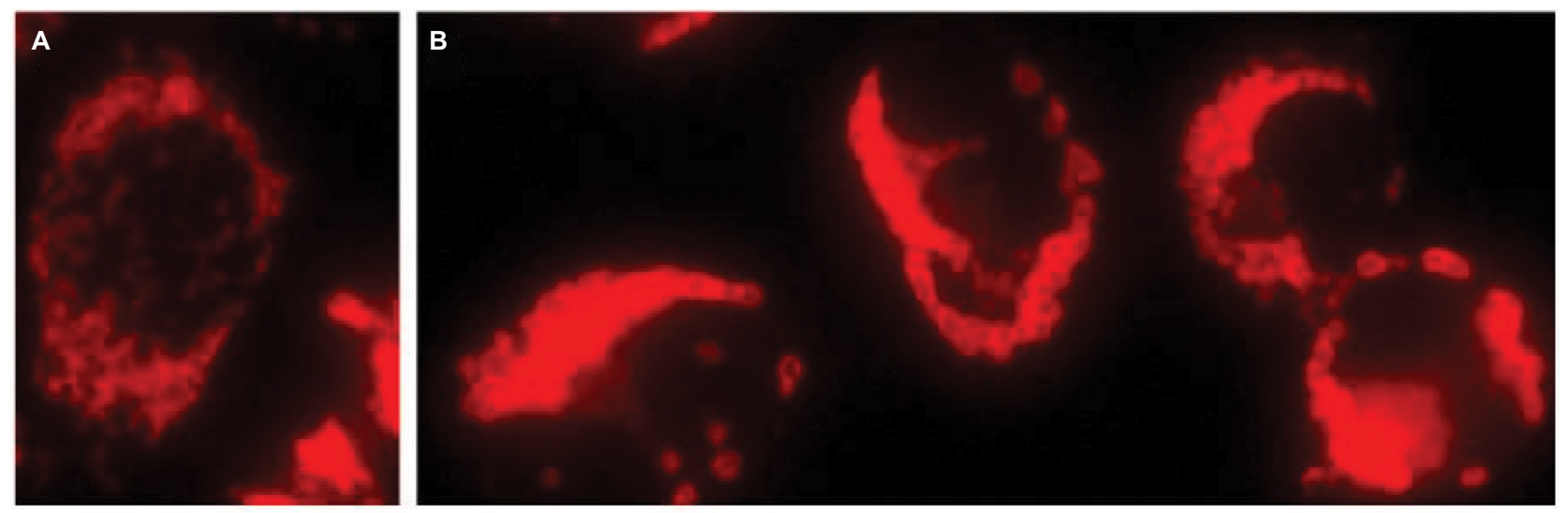

C

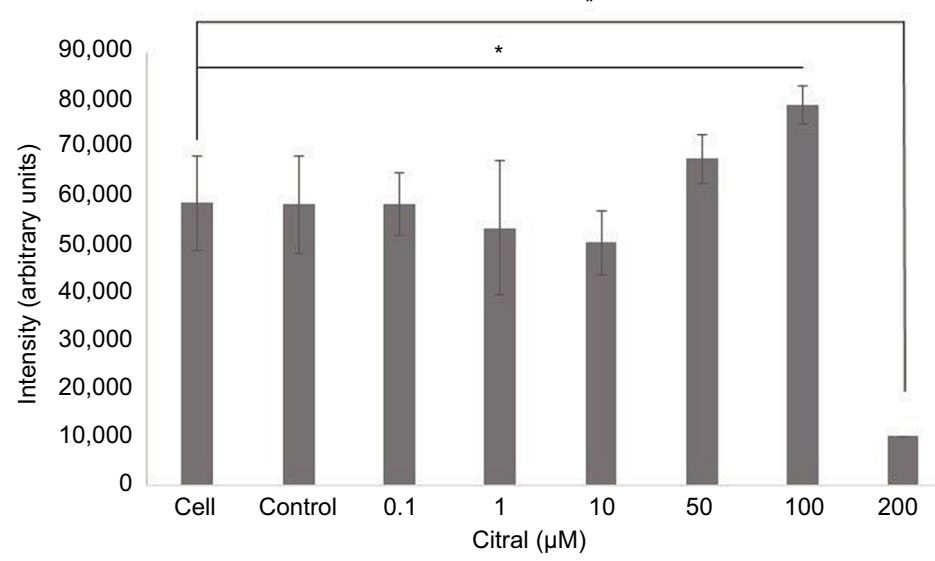

D 300

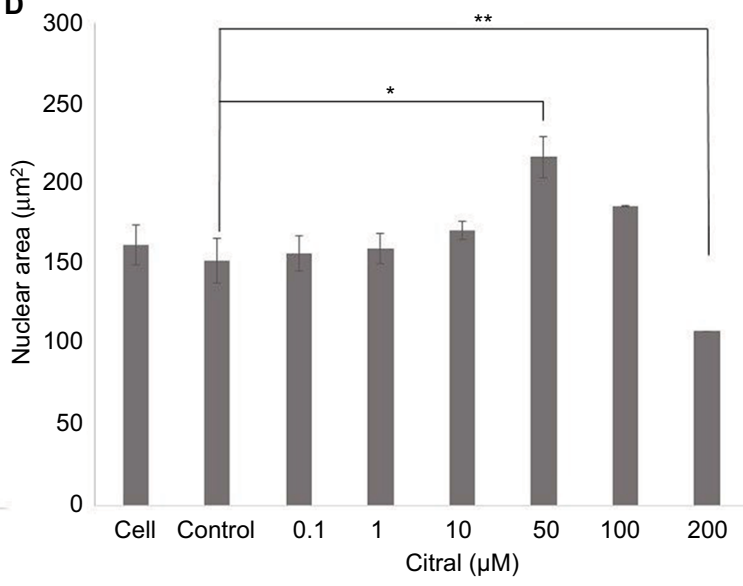

Figure 2 High throughput microscopy was used to assess the changes in mitochondria and nuclei in RD cells in the presence of micromolar concentrations of citral. Images of (A) control, untreated cells and (B) cells treated with $10 \mu \mathrm{M}$ citral. Magnification $\times 40$. Quantification from images of (C) mitochondrial area in the cell and (D) nuclear area per cell. Significance was tested using a two-tailed $t$-test compared to the untreated cells for each cell line $\left({ }^{*} p \leq 0.05, * * p \leq 0.0 \mathrm{I}\right)$.

area of the nucleus and the mitochondria within the cell samples. Lower concentrations of citral were used to see the changes that occurred prior to cell death. At a concentration of $100 \mu \mathrm{M}$ citral, there was a significant increase in the amount of mitochondria; this was followed by a dramatic decrease at $200 \mu \mathrm{M}$ citral (Figure 2C). Prior to apoptotic death, it is well established that MPT leads to an increase in the permeability of the mitochondrial inner membrane, allowing the transmission of solutes and subsequent swelling. At a critical point, this is then followed by a rupture of the membranes.

In addition to the changes seen in the mitochondria during apoptosis, nuclear changes may also occur. In some degenerating cells, swelling of the nucleus can occur, resulting in a large nucleus with abundant heterochromatin set in a watery milieu, which may or may not contain the remains of the euchromatin. ${ }^{18}$ This appears to be the case after incubation with $50 \mu \mathrm{M}$ citral, where a significant increase $(p \leq 0.05)$ in the area of the nuclei is seen. However, more commonly, the degeneration of cells is accompanied by shrinkage and increased condensation. This can be seen in Figure 2D in which incubation with $200 \mu \mathrm{M}$ citral shows a statistically significant $(p \leq 0.01)$ reduction in nuclear area. The chromatin undergoes a phase change from a heterogeneous genetically active network to a highly condensed, inert form. ${ }^{19}$ The underlying mechanisms for such events in degenerating or dying cells may be disturbances in the ionic concentration balance and in membrane permeability. ${ }^{20}$

Similar results were also observed with regard to mitochondrial intensity and nuclear area for the RH30 cell line.

\section{Volatility of citral}

The citral itself is a mixture of two geometric isomers, geranial (citral a) and neral (citral b), and is highly volatile. The isomers were determined to occur at a ratio of 57:43 in our sample, as shown by gas chromatography (Figure 3 ). The volatility of the citral was also determined (see Materials and Methods) and found to give an experimental value of 13.53 Pa m $3 / \mathrm{mol}$ for Henry's law constant. This is consistent with the literature values that show estimates of $3.76 \times$ $10^{-4} \mathrm{~atm} \times \mathrm{m}^{3} / \mathrm{mol}\left(38.1 \mathrm{~Pa} \times \mathrm{m}^{3} / \mathrm{mol}\right)$ and $4.35 \times 10^{-5} \mathrm{~atm}$ 


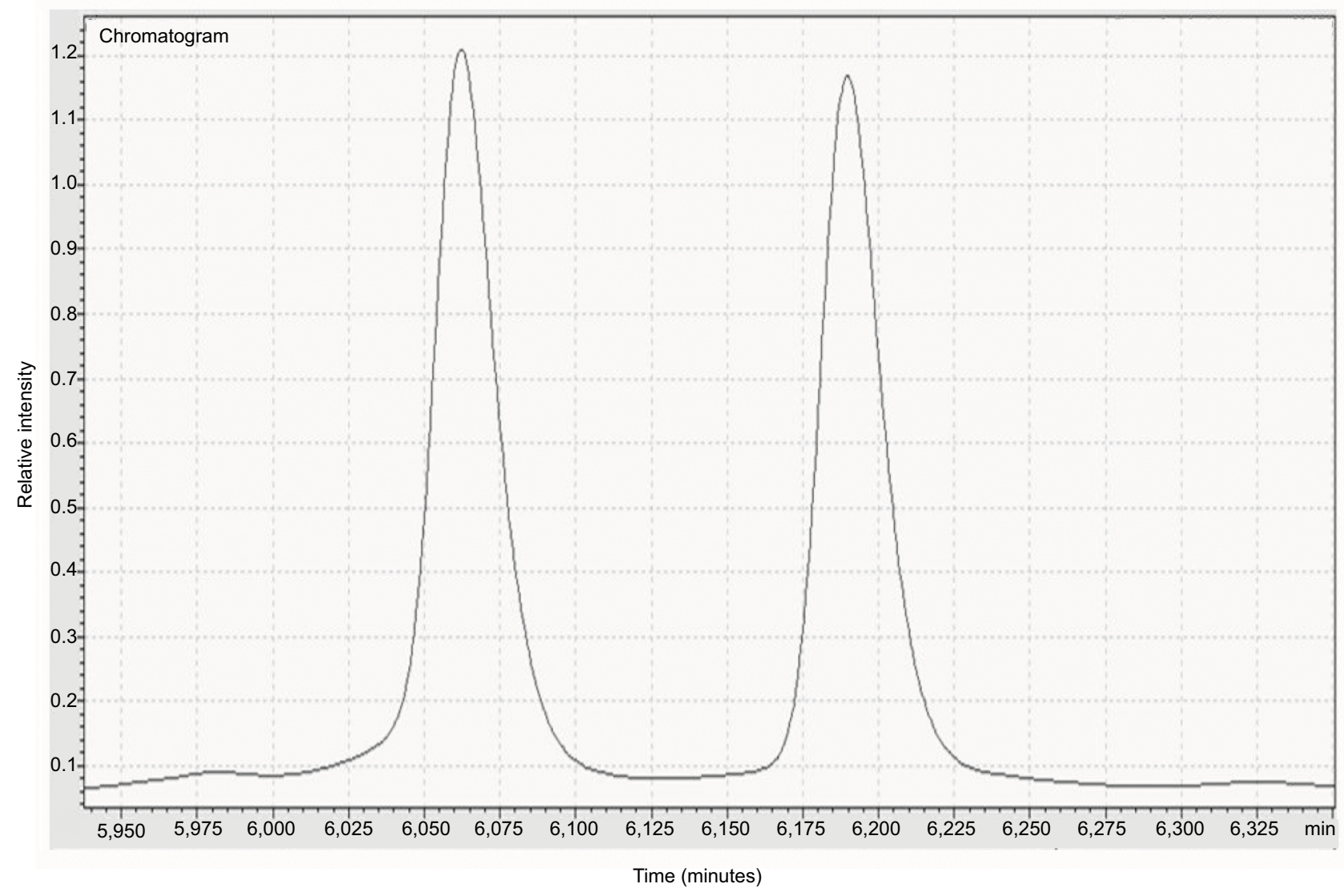

Figure 3 Gas chromatogram showing the ratio of the peaks of the isomers geranial and neral from citral.

$\times \mathrm{m}^{3} / \mathrm{mol}\left(4.41 \mathrm{~Pa} \times \mathrm{m}^{3} / \mathrm{mol}\right.$; at $25^{\circ} \mathrm{C}$ each $)$ using the bond and group method, respectively. ${ }^{22}$

Within the plant, such constituents of essential oils are protected by compartmentation, ${ }^{23}$ but once extracted they are prone to oxidative damage, chemical transformations, or polymerization reactions. It is this change that occurs to free citral that motivates the packaging into biodegradable and biocompatible BSA nanoparticles.

\section{Physicochemical characteristics of BSA nanoparticles}

The diameter of the nanoparticles was measured from SEM images (Figure 4A), and the diameters of BSA particles and BSA@citral nanoparticles were determined to be 240 $\pm 65 \mathrm{~nm}$ and $180 \pm 45 \mathrm{~nm}$, respectively, after measuring the diameter of 20 nanoparticles for each sample from SEM images. Similarly, the hydrodynamic diameter (Figure 4B) of the BSA particles $(255 \pm 52 \mathrm{~nm})$ is larger than that of the BSA@citral nanoparticles (185 \pm 55 nm).

Zeta potentials for the BSA particles and BSA@citral nanoparticles were found to be $-30.5 \pm 5.99 \mathrm{mV}$ and -21.9 $\pm 5.47 \mathrm{mV}$, respectively. Maryam et $\mathrm{al}^{24}$ showed comparable results when preparing carvacrol-loaded HSA particles.
Percentage yield was calculated for both blank and citralloaded nanoparticles as 87 and 94\%, respectively.

The size distribution of the nanoparticles was determined using CPS disc centrifuge, and a polydispersity index of 1.242 and 1.292 was determined for the blank and citral-loaded BSA nanoparticles, respectively (Table 1).

The mechanism of the interaction of the citral with the BSA molecules proceeds via a Markovnikov nucleophilic addition (Schematic 1). This results in reversible bonding, allowing citral to be released in aqueous solution via E2 elimination mechanism.

To determine the total uptake of citral into the BSA nanoparticles, the protein component was totally degraded using trypsin. Trypsin cleaves peptide chains mainly at the carboxyl side of the amino acids lysine or arginine, except when either is followed by proline. The amount of citral released from the complex was then determined by titration and gas chromatography.

In $25 \mathrm{mg}$ of nanoparticles, $28.5 \mu \mathrm{M}$ of citral was found, i.e., $1.14 \mu \mathrm{M}$ citral $/ \mathrm{mg}$ nanoparticle. This value was then taken as the maximum amount of citral that could be released from the BSA@citral nanoparticles (Figure 5; maximum release). 


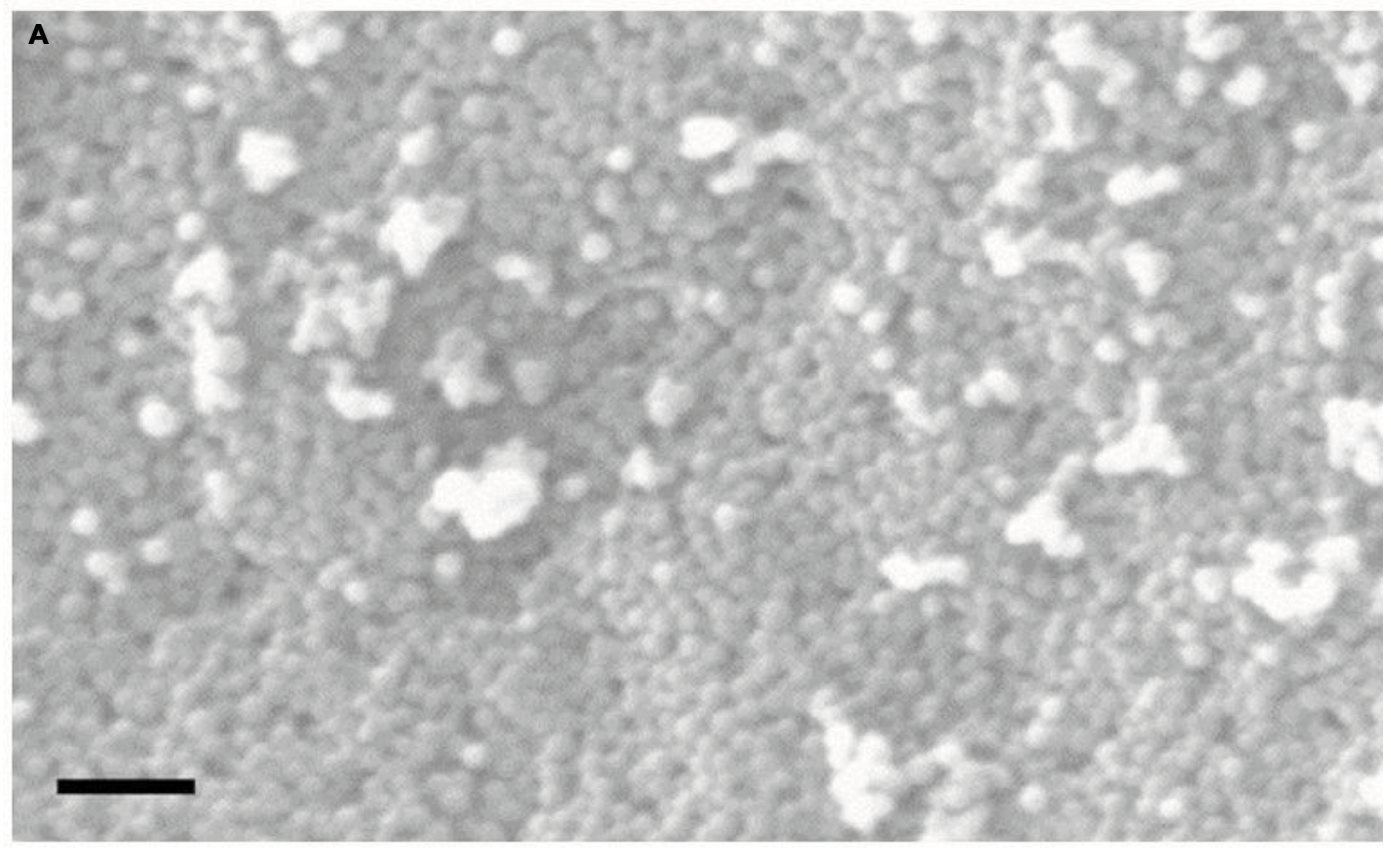

B

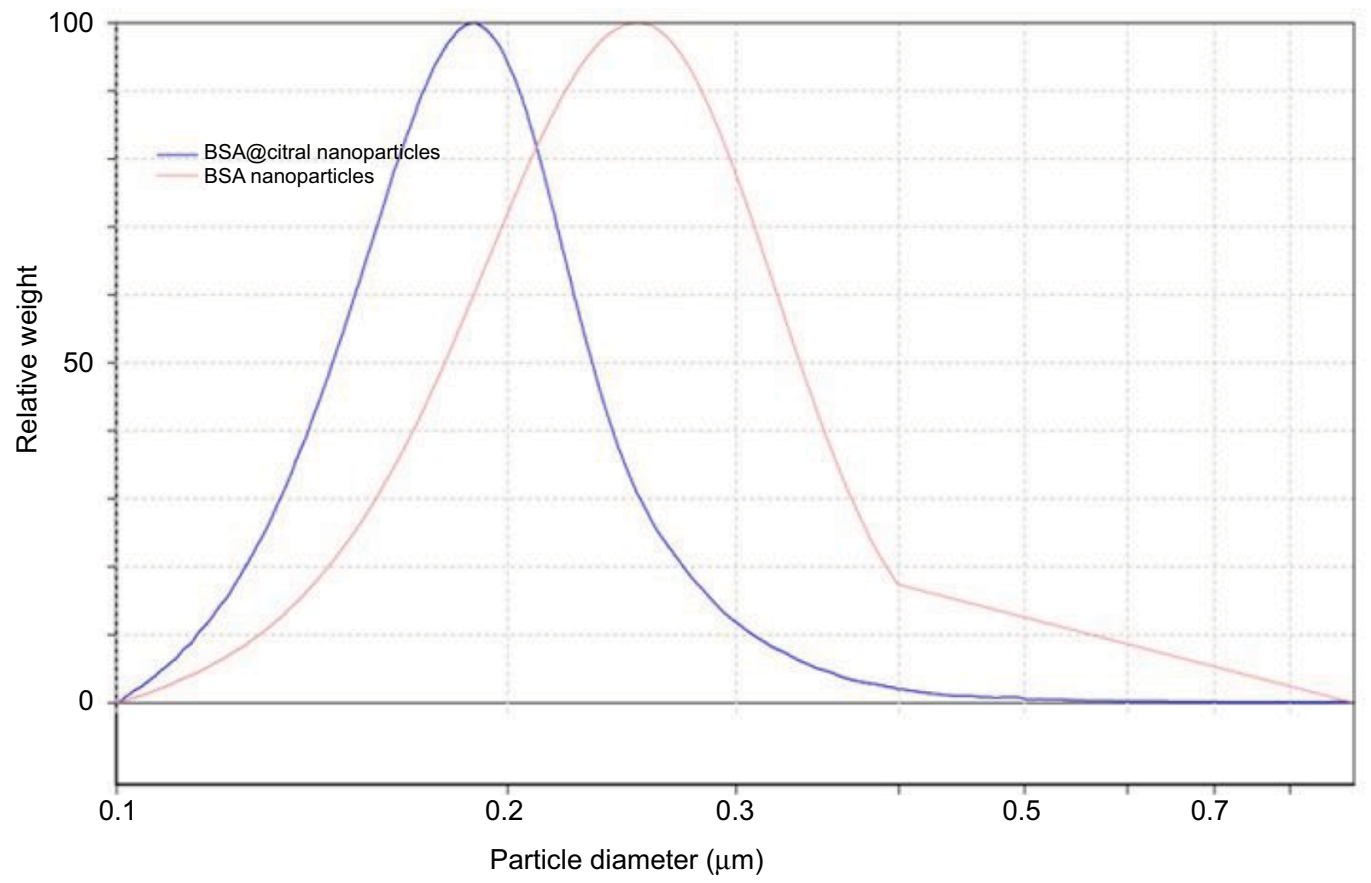

Figure 4 BSA nanoparticles were prepared by the desolvation method. (A) SEM image of the nanoparticles. Scale bar shown is I $\mu \mathrm{m}$. (B) Size and distribution of the BSAloaded and unloaded nanoparticles as determined by CPS disc centrifuge (CPS Instruments Europe, Oosterhout, the Netherlands).

Abbreviations: BSA, bovine serum albumin; SEM, scanning electron microscopy.

\section{In vitro release of citral from BSA nanoparticles}

The citral-loaded nanoparticles were incubated with RMS cells, and the proliferation rate determined after $24 \mathrm{~h}$ of incubation. It can be seen from Figure 6 that the unloaded BSA nanoparticles (BSA@0C) showed no significant effect on proliferation, confirming their biocompatibility. The decrease in cell proliferation with increasing citral concentrations indicates that citral is being released from the BSA nanoparticles and entering the cells. There was no significant difference on the effects of citral between the two RMS cell lines. 
Table I Summary of the physicochemical properties of the BSA and BSA@citral nanoparticles

\begin{tabular}{llllllll}
\hline & $\begin{array}{l}\text { Diameter } \\
\text { SEM }(\mathbf{n m})\end{array}$ & $\begin{array}{l}\text { Diameter } \\
\text { CPS }(\mathbf{n m})\end{array}$ & PDI & SD & $\begin{array}{l}\text { Zeta } \\
\text { potential } \\
(\mathbf{m V})\end{array}$ & $\begin{array}{l}\text { Encapsulation } \\
\text { efficiency } \\
\text { (\% uptake) }\end{array}$ & $\begin{array}{l}\text { Percentage } \\
\text { yield }\end{array}$ \\
\hline Blank nano & 240 & 255 & 1.242 & 0.0409 & -30.5 & $\mathrm{n} / \mathrm{a}$ & 87 \\
Citral loaded & 180 & 185 & 1.292 & 0.1409 & -21.9 & 67 & 94 \\
\hline
\end{tabular}

Note: $\mathrm{n} / \mathrm{a}$ indicates no data.

Abbreviations: BSA, bovine serum albumin; SEM, scanning electron microscopy; PDI, polydispersity index.<smiles>[R]SCC[C@@H](C)CCC=C(C)C</smiles>

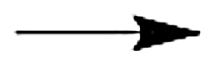<smiles>[R]S[Z](C)(CC=O)CCC=C(C)C</smiles>

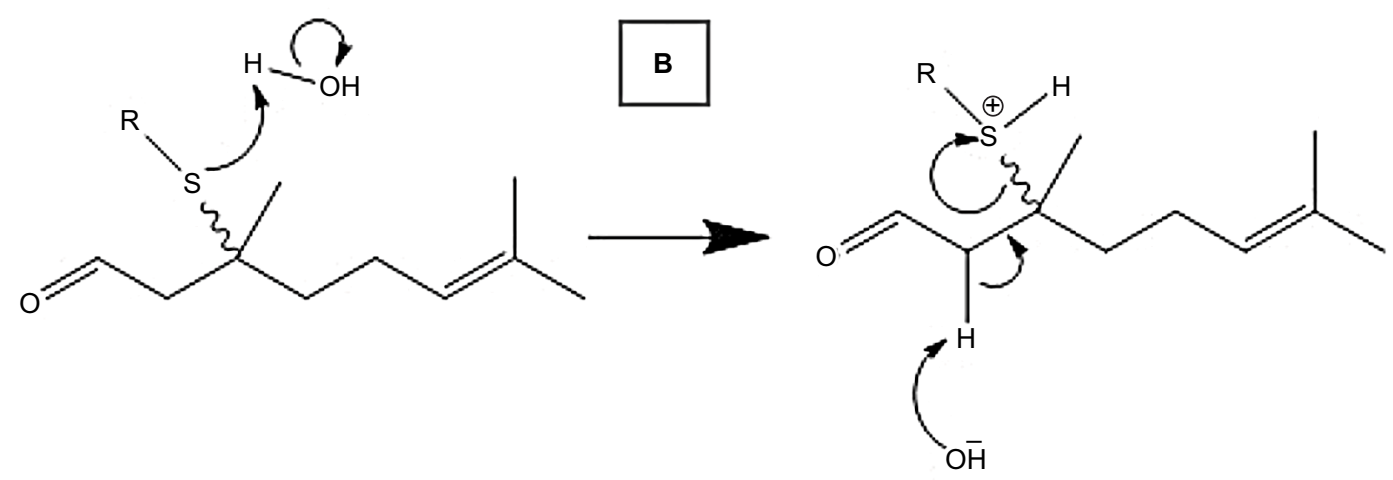<smiles>CCCCCCCCCCCC=O</smiles>

Schematic I Proposed mechanism of the reversible bonding between BSA thiol groups and citral. The Markovnikov product of the E isomer of citral is shown, although the differing isomers of citral give the same product. (A) Binding of citral to BSA and (B) release of citral from BSA in aqueous solution.

Abbreviations: BSA, bovine serum albumin.

\section{Release profile of nanoparticle-loaded polymer wafers}

While the nanoparticles are effective at protecting the volatile compound, and can be directed to tumors by either passive or active targeting, polymer wafers can be used to delivery locally higher doses of chemotherapy directly to a tumor bed after removal. We therefore investigated the generation of polymer wafers with embedded BSA@citral nanoparticles.

BSA@citral nanoparticles (25 mg) containing $1.14 \mu \mathrm{M}$ of citral $/ \mathrm{mg}$ nanoparticles were embedded in $0.3 \mathrm{~g}$ of SA polymer. We chose to use a polyanhydride since the polymer 


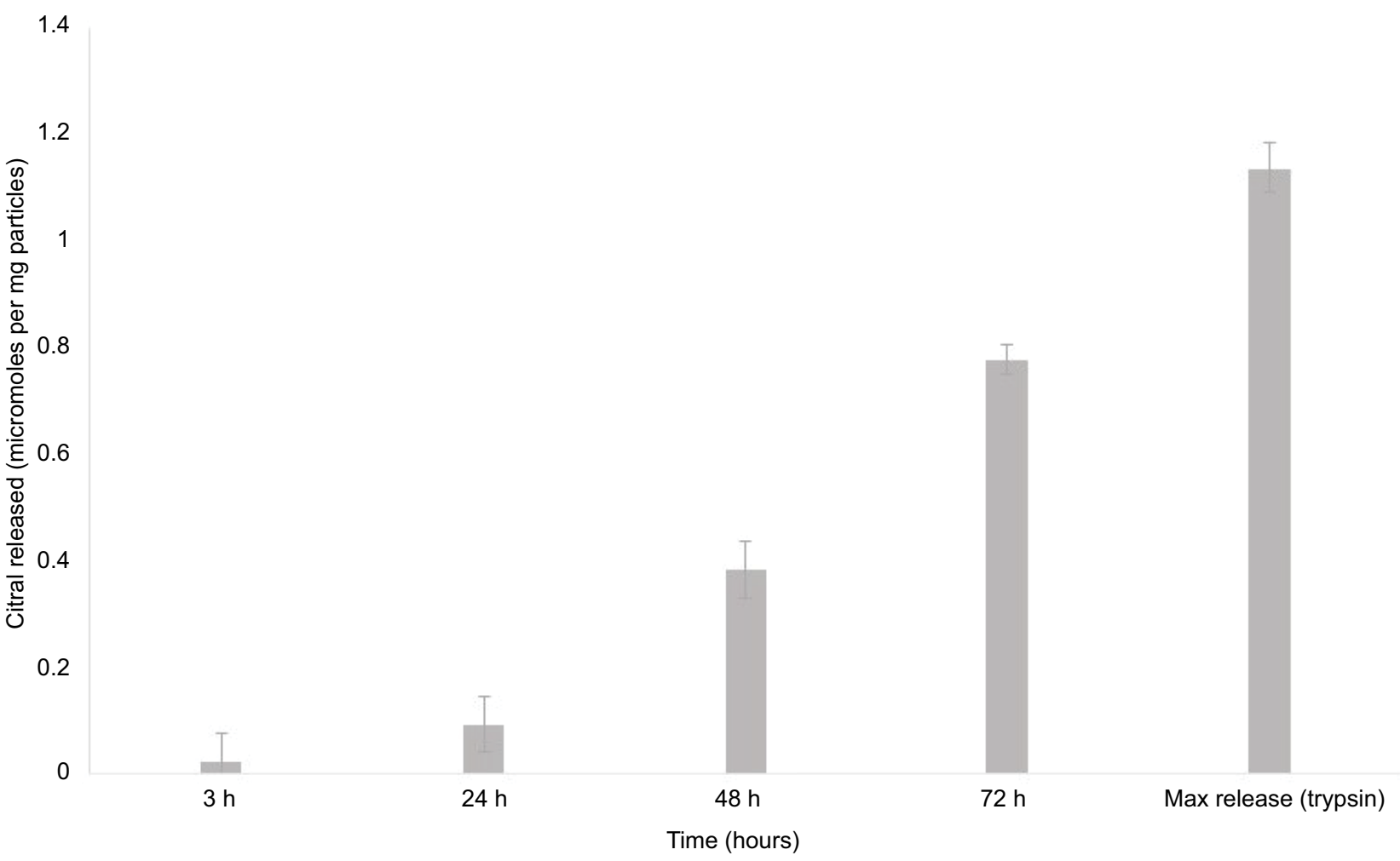

Figure 5 The release profile of citral from 25 mg BSA@citral nanoparticles was determined over 72 h. The maximum release was determined by the dissolution of the BSA particle with trypsin.

Abbreviation: BSA, bovine serum albumin.

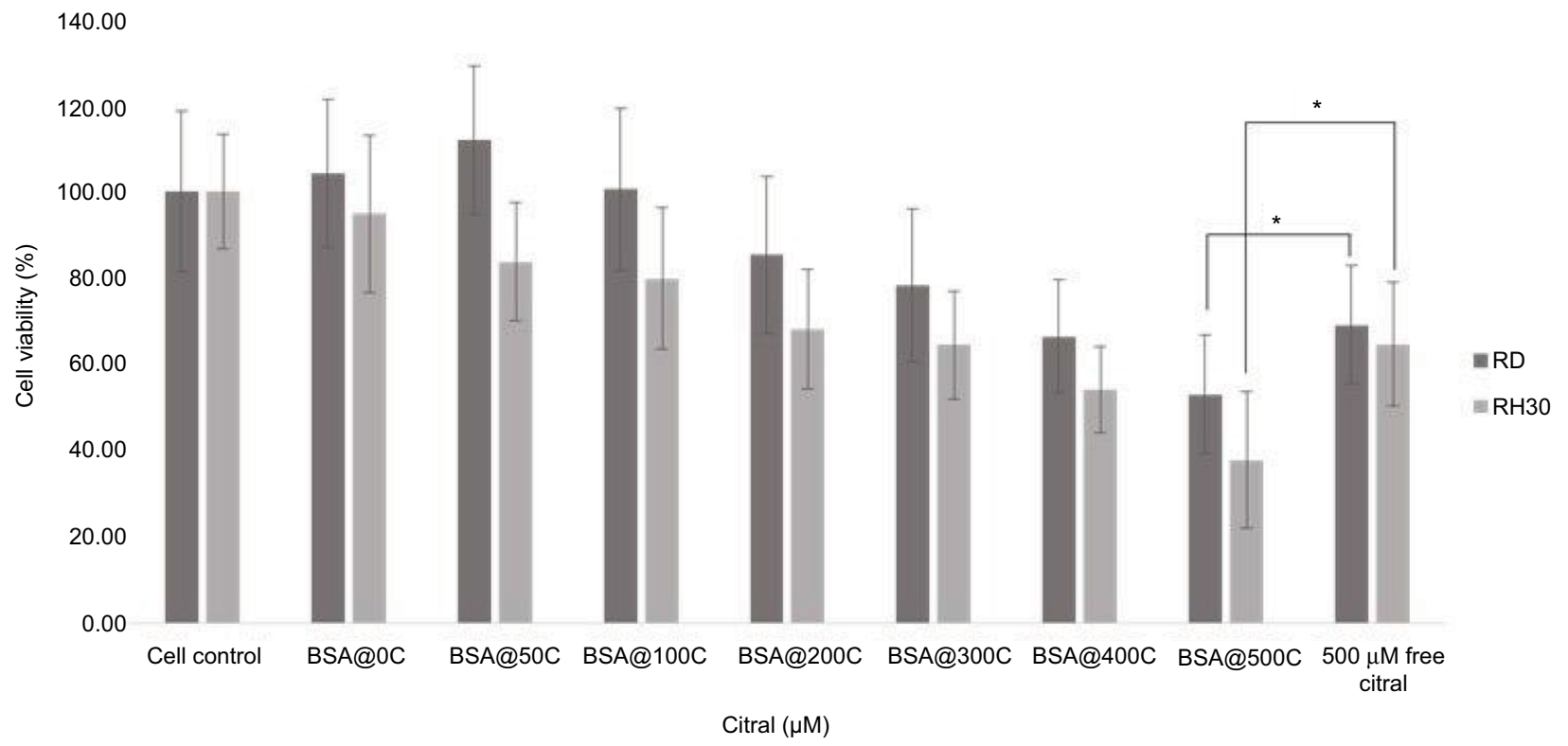

Figure 6 Cell viability in the presence of BSA and BSA@citral nanoparticles was determined. The nanoparticles were incubated with either RD or RH30 cells for 24 h, before cell counting (sample replicates $n=6$, experimental replicates $n=2$ ). The number @ $\times$ C indicates the citral concentration in $\mu M$. In total, $500 \mu M$ of free citral was also included for comparison. The cell only control was set to $100 \%$, and all data were scaled relative to the cell only control. Significance was tested using a two-tailed $t$-test to compare the bound citral (BSA@500C) to free citral $(500 \mu \mathrm{M})$ for each cell line $(* p \leq 0.05)$.

Abbreviation: BSA, bovine serum albumin. 
is biodegradable and has been previously shown to have widespread applications in the controlled delivery of drugs. ${ }^{25}$

Anhydrides are highly susceptible to hydrolysis and degrade into non-toxic diacid monomers that can be metabolized and excreted from the body (polymer properties database). However, purely aromatic polyanhydrides may become brittle, which causes eventual fragmentation after exposure to water. This means that water-soluble drugs would be rapidly released, rather than the gradual release by polymer erosion. Copolymers of aromatic anhydrides and anhydrides prepared from fatty acids, such as the natural SA, have controlled degradation rates varying from days to years. ${ }^{26}$

To examine the biodegradability of the wafer, we monitored the mass, and physical appearance, of the wafer over 40 days. The physical appearance of the wafer at the beginning of the trial is shown in Figure 7A and B and an SEM of the surface is shown in Figure 7C. The polymer wafer was then incubated in PBS and seen to degrade over the trial period. This correlated to a linear decrease in mass to $28.2 \%$ of the original mass over a period of 40 days (Figure 7D). We then examined the release of citral from the nanoparticles embedded in the wafer. Drug release from polymer matrices can be complex, and is governed by both diffusion and erosion. ${ }^{27} \mathrm{~A}$ burst phase or initial high drug release soon after administration is typical of most systems, and this is seen in our system (Figure 7E).

Samples from the incubation media were taken over the 40-day time period and the concentration of citral was assessed by UV absorption at $230 \mathrm{~nm}$. This amounted to a release of $72 \%$ of the total citral load. The drug dosage can also be easily altered by adjusting the nanoparticle loading in the wafer.

The wafers created here are similar to the Gliadel wafers used clinically to provide chemotherapy for brain tumors, although these dissolve over 2-3 weeks and release carmustine into the tumor bed. Within the tumor bed, the surgeon
A

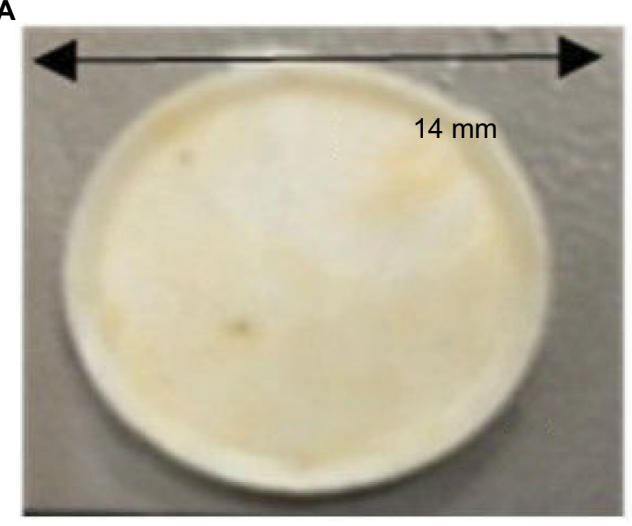

B
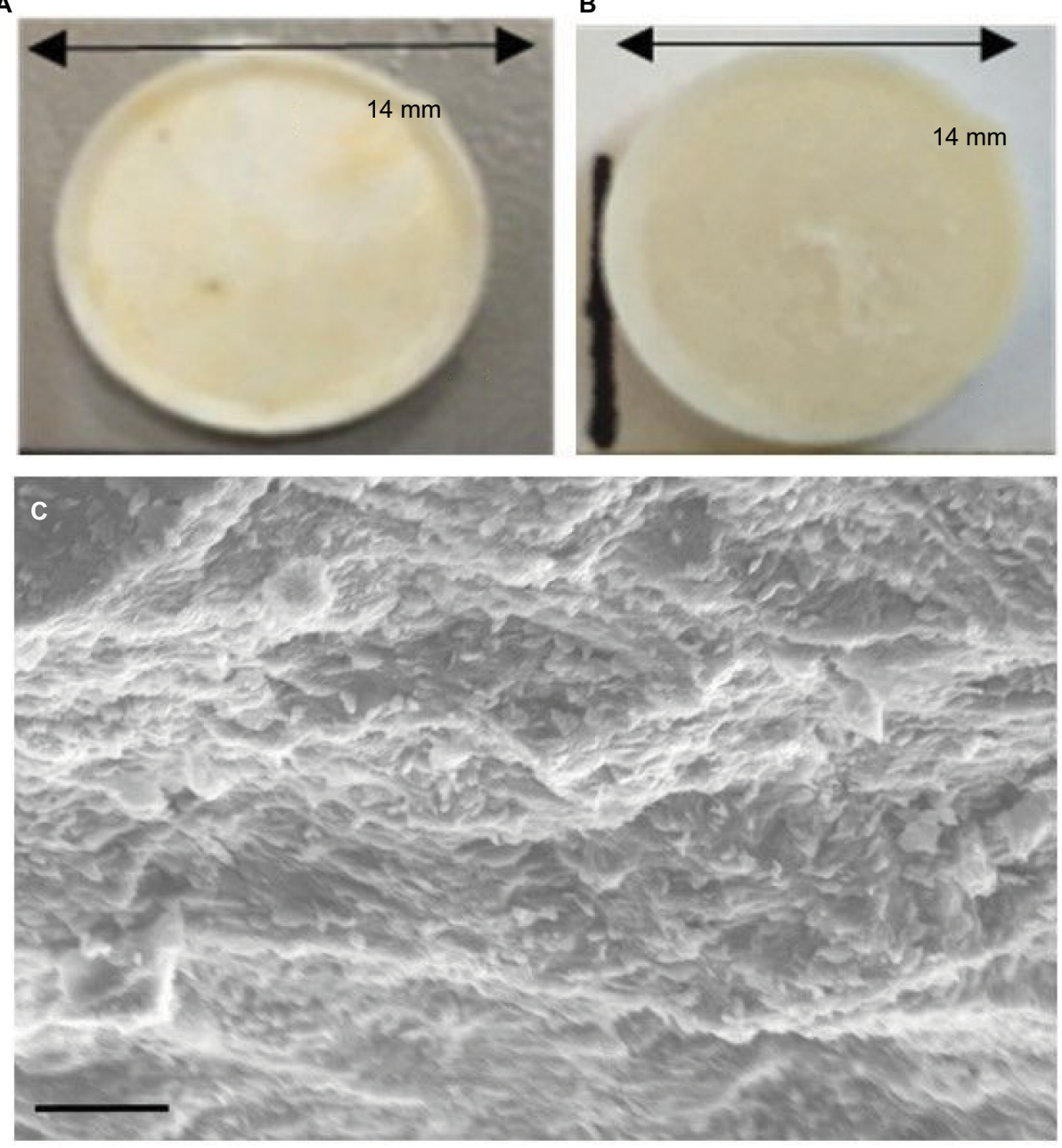

Figure 7 (Continued) 
D

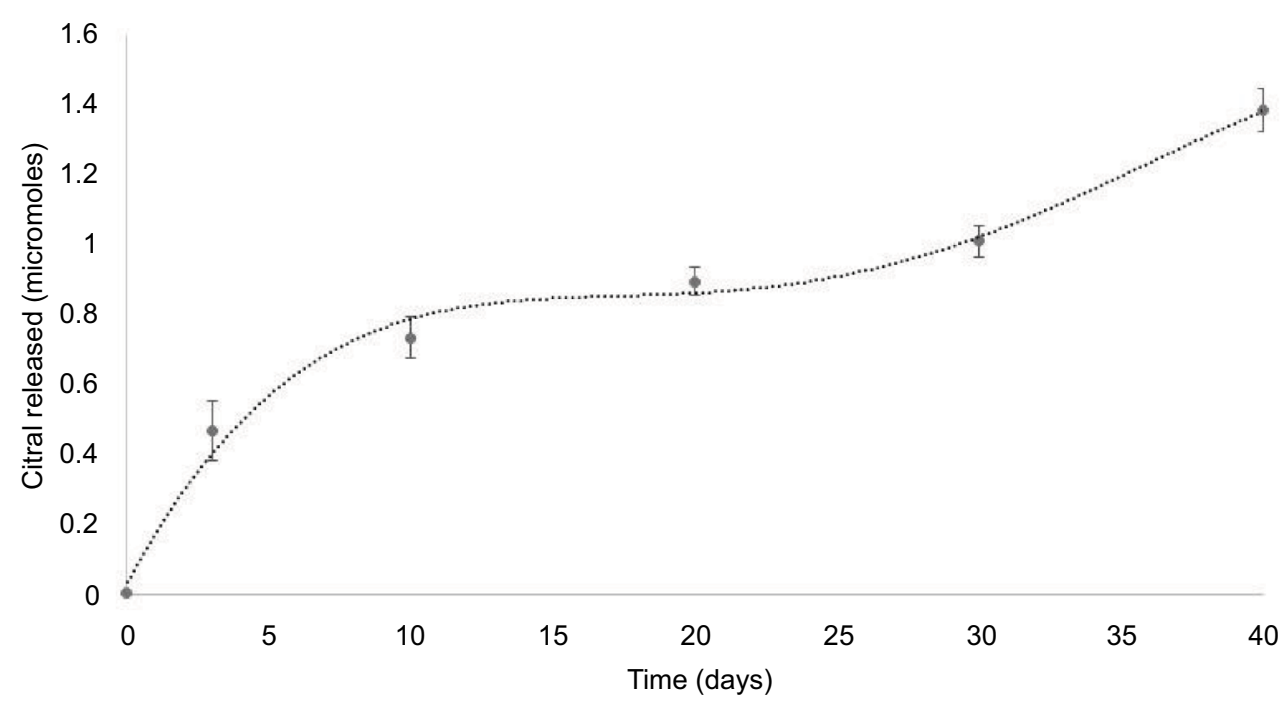

E

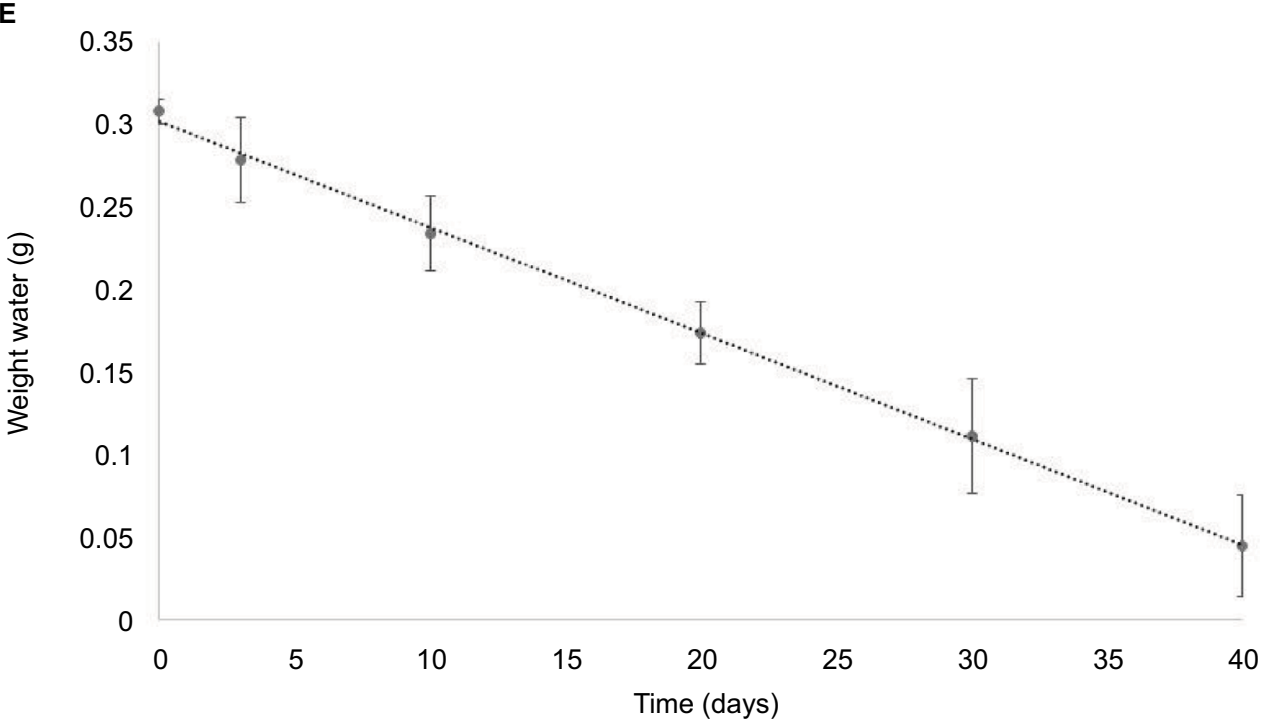

Figure 7 BSA nanoparticles were embedded into polyanhydride wafers. Photograph of the wafer embedded with (A) control BSA nanoparticles and (B) BSA@citral nanoparticles. SEM images of the surface of the wafer (C); scale bar shown is $20 \mu \mathrm{m}$. (D) Graph shows the decrease in the mass of the wafer with embedded BSA@citral nanoparticles after incubation in PBS over the course of 40 days. (E) Graph shows the release of citral into the PBS media.

Abbreviations: BSA, bovine serum albumin; SEM, scanning electron microscopy; PBS, phosphate-buffered saline.

can insert several of the wafers to give the right dose of drug to ensure that any remaining cancer cells are mopped up.

\section{Conclusion}

In summary, we have demonstrated that citral is an active compound that can induce cell death in immortalized cancer cells. We have demonstrated that the compound can be packaged in nanoparticles for improved stability of the compound and to take advantage of the EPR effect in vivo. Furthermore, the use of biodegradable wafers permits the release of the compound over an extended period, which could be used to prevent reoccurrence of cancerous cells in the tumor bed after surgical removal. ${ }^{28}$

\section{Acknowledgments}

The authors would like to thank Dr Cindy Huang for help with SEM imaging. BW would like to thank Prof Michael Whittlesey, University of Bath, for providing assistance with pressing the polymeric wafers. The authors would also like to thank Williams Fund for their ongoing support. 


\section{Disclosure}

The authors report no conflicts of interest in this work.

\section{References}

1. Kar A. Pharmacognosy and Pharmacobiotechnology. New Delhi: New Age International Ltd Publishers; 2003:316.

2. Dudai N, Weinstein Y, Krup M, Rabinski T, Ofir R. Citral is a new inducer of caspase-3 in tumor cell lines. Planta Med. 2005;71(5):484-488.

3. Xia H, Liang W, Song Q, Chen X, Chen X, Hong J. The in vitro study of apoptosis in NB4 cell induced by citral. Cytotechnology. 2013;65(1):49-57.

4. Kapur A, Felder M, Fass L, et al. Modulation of oxidative stress and subsequent induction of apoptosis and endoplasmic reticulum stress allows citral to decrease cancer cell proliferation. Sci Rep. 2016;6:27530.

5. Patel PB, Thakkar VR, Patel JS. Cellular effect of curcumin and citral combination on breast cancer cells: induction of apoptosis and cell cycle arrest. J Breast Cancer. 2015;18(3):225-234.

6. Esterbauer H, Zollner H, Scholz N. Reaction of glutathione with conjugated carbonyls. Z Naturforsch C. 1975;30(4):466-473.

7. Diliberto JJ, Srinivas P, Overstreet D, Usha G, Burka LT, Birnbaum LS. Metabolism of citral, an alpha, beta-unsaturated aldehyde, in male F344 rats. Drug Metab Dispos. 1990;18(6):866-875.

8. Scott RPW. Essential oils. In: Worsfold P, Townshend A, Poole C, editors. Encyclopedia of Analytical Science. 2nd ed. London: Elsevier; 2005:554-561.

9. Ravi Kumar MN. Nano and microparticles as controlled drug delivery devices. J Pharm Pharm Sci. 2000;3(2):234-258.

10. Yu Z, Yu M, Zhang Z, Hong G, Xiong Q. Bovine serum albumin nanoparticles as controlled release carrier for local drug delivery to the inner ear. Nanoscale Res Lett. 2014;9(1):343.

11. Viollet B, Guigas B, Sanz Garcia N, LeClerc J, Foretz M, Andreelli F. Cellular and molecular mechanisms of metformin: an overview. Clin Sci (Lond). 2012;122(6):253-270.

12. Wolinsky JB, Colson Y, Grinstaff MW. Local drug delivery strategies for cancer treatment: gels, nanoparticles, polymeric films, rods, and wafers. J Control Release. 2012;159(1):14-26.

13. Shackney SE, McCormack GW, Cuchural GJ Jr. Growth rate patterns of solid tumors and their relation to responsiveness to therapy: an analytical review. Ann Intern Med. 1978;89(1):107-121.

14. Meyer JS. Growth and cell kinetic measurements in human tumors. Pathol Annu. 1981;16(Pt 2):53-81.
15. Zheng S, Jing G, Wang X, Ouyang Q, Jia L, Tao N. Citral exerts its antifungal activity against Penicillium digitatum by affecting the mitochondrial morphology and function. Food Chem. 2015;178: 76-81.

16. Liu X, Hajnóczky G. Altered fusion dynamics underlie unique morphological changes in mitochondria during hypoxia-reoxygenation stress. Cell Death Differ. 2011;18(10):1561-1572.

17. Sesso A, Belizário JE, Marques MM, et al. Mitochondrial swelling and incipient outer membrane rupture in preapoptotic and apoptotic cells. Anat Rec (Hoboken). 2012;295(10):1647-1659.

18. Branstetter D, Goldblatt P. Pathobiology of the nuclear envelope. In: Trump BF, Laufer A, Jones RT, editors. Cellular Pathobiology of Human Disease. New York: Gustav Fischer; 1983:73-97.

19. Toné S, Sugimoto K, Tanda K, et al. Three distinct stages of apoptotic nuclear condensation revealed by time-lapse imaging, biochemical and electron microscopy analysis of cell-free apoptosis. Exp Cell Res. 2007;313(16):3635-3644.

20. Blackburn WR. Pathobiology and nucleocytoplasmic exchange. Pathobiol Annu. 1971;1:1-31.

21. Rong Y, Gregson C, Parker A. Thermogravimetric measurements of liquid vapor pressure. J Chem Thermodyn. 2012;51:25-30.

22. Meylan WM, Howard PH. Bond contribution method for estimating Henry's Law Constants. Environ Toxicol Chem. 1991;10:1283-1293.

23. Treibs W, Merkel D. E. Gildemeister/ Fr. Hoffmann: Die ätherischen Öle Band IIIa. 4th ed. Berlin: Akademie-Verlag; 1960

24. Maryam K, Shakeri S, Kiani K. Preparation and in vitro investigation of antigastric cancer activities of carvacrol-loaded human serum albumin nanoparticles. IET Nanobiotechnol. 2015;9(5):294-299.

25. Vogel BM, Mallapragada SK, Narasimhan B. Rapid synthesis of polyanhydrides by microwave polymerization. Macromol Rapid Commun. 2004;25(1):330-333.

26. Cristescu R, Cojanu C, Popescu A, et al. Processing of poly(1,3bis-( $p$-carboxyphenoxy propane)-co-(sebacic anhydride)) 20:80 (P(CPP:SA)20:80) by matrix-assisted pulsed laser evaporation for drug delivery systems Appl Surf Sci. 2007;254:1169-1173.

27. Boateng JS, Matthews KH, Auffret AD, Humphrey MJ, Stevens HN, Eccleston GM. In vitro drug release studies of polymeric freeze-dried wafers and solvent-cast films using paracetamol as a model soluble drug. Int J Pharm. 2009;378(1-2):66-72.

28. Phale T, Agnihotri J, Khale A. Technical advancement in biodegradable polymers and their recent patents. Int J Res Dev Pharm Life Sci. 2013;3(1):766-774.
Nanotechnology, Science and Applications

\section{Publish your work in this journal}

Nanotechnology, Science and Applications is an international, peer-reviewed, open access journal that focuses on the science of nanotechnology in a wide range of industrial and academic applications. It is characterized by the rapid reporting across all sectors, including engineering, optics, bio-medicine, cosmetics, textiles, resource sustainability and science. Applied research into nano-materials, particles, nano-structures and fabrication, diagnostics and analytics, drug delivery and toxicology constitute the primary direction of the journal. The manuscript management system is completely online and includes a very quick and fair peer-review system, which is all easy to use. Visit http://www.dovepress.com/ testimonials.php to read real quotes from published authors. 